\author{
Military Technical College \\ Kobry Elkobbah, \\ Cairo, Egypt
}



ICCAE

\title{
The behaviour of the Blast Waves Propagation in the Urban Spatial Organizations
}

\author{
EHAB HANAFI MAHMOUD* \\ ehabhm@hotmail.com
}

\begin{abstract}
The patterns of our town and city centres will continue to change as the needs and orientations of our society change. Today the city centres face real challenges. They must respond to the changing needs and demands of modern-day living if they are to survive. They must provide places, which are attractive, welcoming and safe. City centres come to terms with changing circumstances at the end of the twentieth century. One of these circumstances is terrorism.
\end{abstract}

Terrorism has been increasing in scale in recent years, and its style has widened. Since the success of the terrorist attack depends on his propaganda, the terrorists strategy has turned to use the city centre facilities as a target for terrorist attacks.

Although, the risk to any individual structure of becoming the object of a terrorist attack is very small, analysis of terrorist attacks in the last decade indicates that this risk is greatest for facilities in city centres and public spaces. In this case the entire urban environment experiences the effects of the blast wave, which can cover miles of the surrounding areas.

This paper presents the findings from the phase of a programme of research which explores the protection offered the influence of spatial organizations in urban environments, as assessed using the AUTODYN simulation package 3D V3.1.17

\section{KEY WORDS}

Architecture, Urban Planning, Structures, Blast.

\footnotetext{
* Permanent staff (PhD) - Architecture Department. Military Technical Collage - Cairo, EGYPT
} 


\section{BACKGROUND}

Traffic engineers, according to their traffic roles, classified urban streets to four major types. The relationship between the urban street types is illustrated in figure 1. [2]
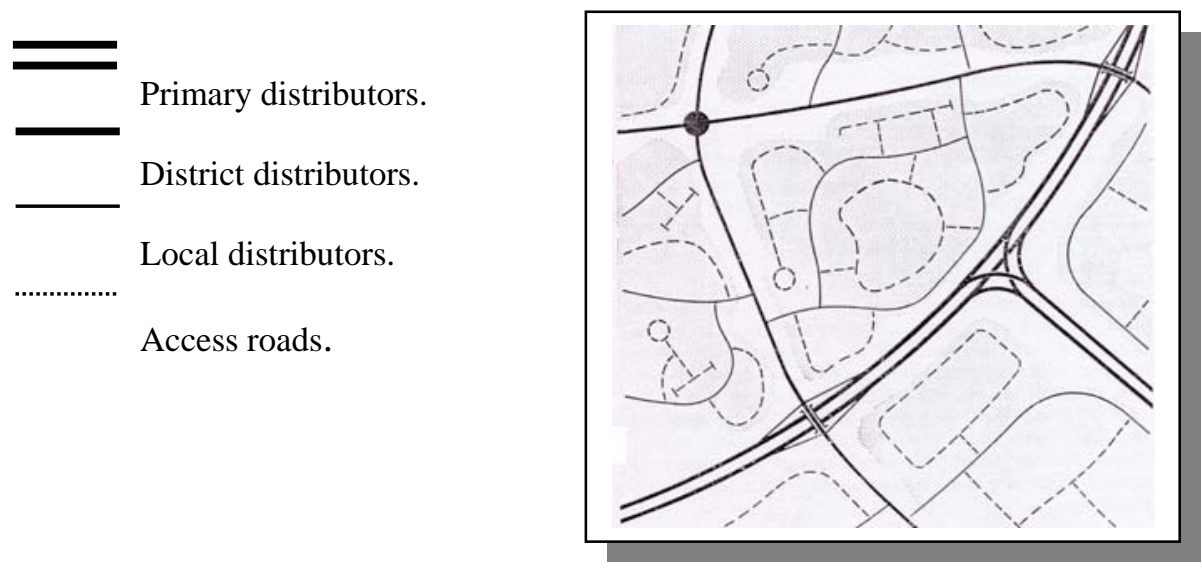

Fig.1. The relationship between urban street types

\section{A. Primary Distributors:}

a) Long distance through traffic serves cities as a whole.

b) Threat prediction from vehicle bomb for this street type is very neglected. The design roles for this type of streets is restricted with no buildings are established on sides of this type of streets.

\section{B. District Distributors:}

a) Through traffic linking main districts within town/city.

b) Threat prediction from vehicle bomb for this street types is consider low. There are some of vulnerable installations, which could be subject to terrorist attacks, locate on the sides of these streets.

\section{Local Distributors:}

a) Serves specific localities comprised of groups of environmental areas, such as the town/city centres or large residential districts, which be bounded but not crossed by district distributors.

b) Threat prediction from vehicle bomb for this street type is considering very high. The local distributors are main grids, which use in town/city centres planning. This type of streets is considering a collector space for most of the important installations, which could be subject to terrorist attacks and take a location into town/city centres, such as embassies, government and office buildings, ... etc. 


\section{Access Road:}

a) Provides direct access to buildings and land within 'environment areas'.

b) Threat prediction of this type is neglected, especially, if they use to serve residential areas.

- It is clear that the Local Distributor Street (LDS) consider the most urban street types, which can be classified as a vulnerable street type. From this point, this paper will investigate, by simulate and analysis of results, all possible spatial organizations of this street type to identify, which can offer reductions in the effects of the blast through the urban environment of the street.

\section{PARAMETER AND LIMITS OF SIMULATIONS}

The limits of the simulations were defined by groups of test simulations, which were analyzed carefully to define the most appropriate design limits, taking in consideration the following parameters:

1) LDS configurations.

2) Spatial organizations of Urban Street.

3) Reference scenario.

\section{LDS Configurations:}

\section{A. Street length:}

Figure 2 \& Table 1 present minimum length of various types of urban street, which can identify by sub-streets. It is clear that 90 meters is an acceptable length of the Local Distributor Street, as a target urban street in this paper, for all purposes into town/city centres.

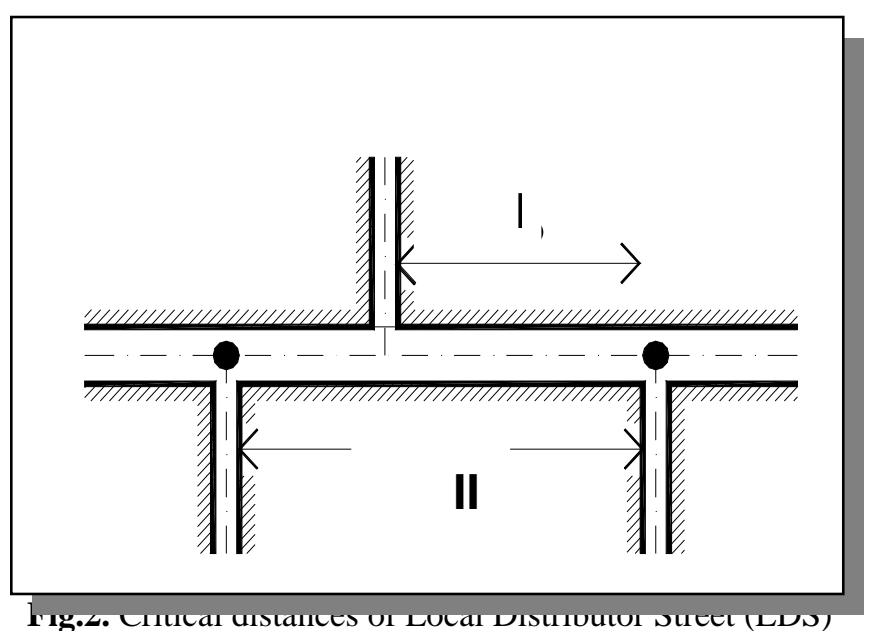

Table 1. Minimum length of various types of urban street [2] 


\begin{tabular}{|l|c|c|}
\hline All-purpose street & \multicolumn{2}{|c|}{ Min. Spacing (m.) } \\
\hline & I & II \\
\hline Primary Distributor. & 275 & $*$ \\
\hline District Distributor. & 200 & $*$ \\
\hline Local Distributor. & 90 & $*$ \\
\hline Access Road. & 90 & \\
\hline Residential roads & \multicolumn{2}{|}{} \\
\hline Local Distributor. & 90 & 40 \\
\hline Major access street & 80 & 40 \\
\hline Collector street & 50 & 25 \\
\hline Access street & 30 & 15 \\
\hline Access way & 25 & 10 \\
\hline Mews court & 30 & 20 \\
\hline Housing square & 30 & 15 \\
\hline
\end{tabular}

* No standards exist for this category.

\section{B. Street width:}

Table 2 shows the acceptable total street width of various types of urban street. It is clear that the acceptable total width of LDS, as a target urban street in this paper, for all purposes are about $16 \mathrm{~m}$.

Table 2. Acceptable width of LDS [2]

\begin{tabular}{|c|c|c|c|}
\hline \multirow[b]{2}{*}{ Road type } & \multicolumn{2}{|c|}{ Lane widths } & \multirow[b]{2}{*}{$\begin{array}{l}\text { Acceptable } \\
\text { total width }\end{array}$} \\
\hline & Single two-lane carriageway* & $\begin{array}{l}\text { Dual or divided } \\
\text { carriageway with } \\
\text { at least four lanes. }\end{array}$ & \\
\hline $\begin{array}{l}\text { Primary } \\
\text { Distributor }\end{array}$ & - & $3.6 \mathrm{~m}$. & $55-50 \mathrm{~m}$. \\
\hline $\begin{array}{l}\text { District } \\
\text { Distributor }\end{array}$ & $-3.6 \mathrm{~m}$. & $3.6 \mathrm{~m}$. & $26 \mathrm{~m}$. \\
\hline $\begin{array}{l}\text { Local } \\
\text { Distributor }\end{array}$ & $\begin{array}{ll}\text { - } & 3.6 \mathrm{~m} \text {. in industrial districts. } \\
\text { - } & 3.3 \mathrm{~m} \text {. in principal business } \\
& \text { districts. } \\
\text { - } & 3.0 \mathrm{~m} \text {. in residential districts. }\end{array}$ & - & $16 \mathrm{~m}$. \\
\hline Access Road & $\begin{array}{l}\text { Principal means of access: } \\
-\quad 3.6 \mathrm{~m} . \text { in industrial districts. } \\
-\quad 3.3 \mathrm{~m} . \text { in principal business } \\
\quad \text { districts. } \\
-\quad 2.7 \mathrm{~m} . \text { in residential districts. }\end{array}$ & - & $\begin{array}{l}10 \mathrm{~m} . \\
6 \mathrm{~m} .\end{array}$ \\
\hline
\end{tabular}

*Carriageway: The main part of street, which is used for vehicles’ parking and moving,

\section{The height of the structures}


Corresponding to the analyses of the various positions from which street elevations can be seen, as shown in figure 3, It is clear that there are relationship between width of street and height of buildings, which forms street space. For LDS, the suitable building height is around $17.5 \mathrm{~m}$.

This paper will fix the buildings height, which form the street space, for all the simulations. The assumed reference building characteristics are as follows: 16-m high, reinforced concrete structure system. The typical storey height is $3.00 \mathrm{~m}$, and the first floor is $4.00 \mathrm{~m}$ high.

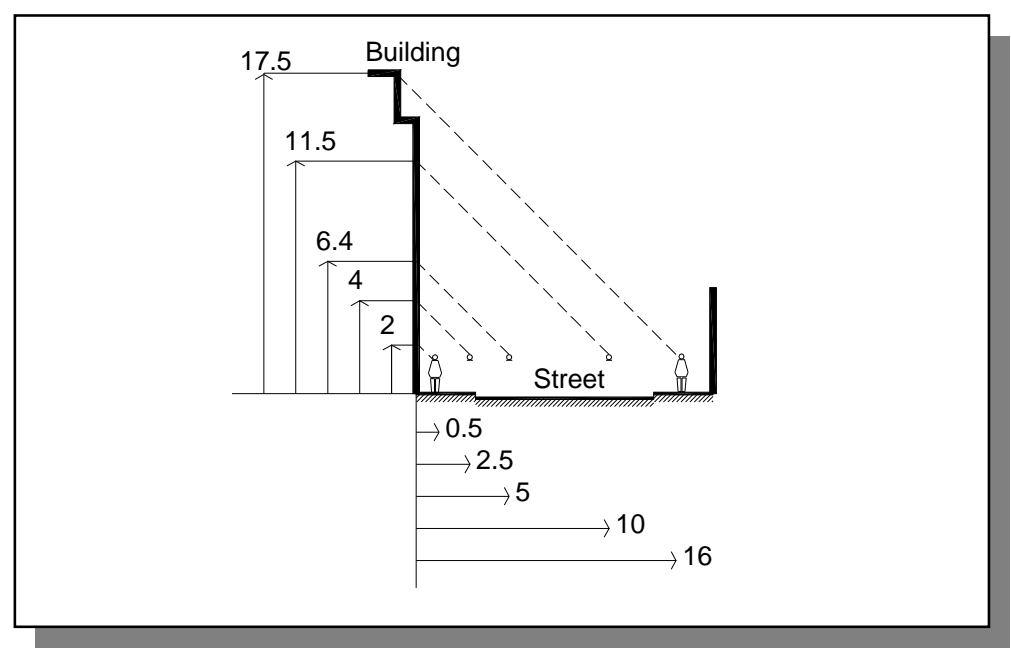

Fig. 3 Minimum viewing distances (m.) [3]

\section{Spatial organizations of Urban Street:}

Twelve major scenarios were investigated as candidate spatial organizations of LDS to identify, which can offer reductions in the effects of the blast. These scenarios are classified into two groups (Fig. 4)

- Group A: Straight Street Shape: as a common street shape.

1. Spatial organizations as parallel linear spaces. [Reference scenario].

2. Spatial organizations as perpendicular linear spaces.

3. Cluster spatial organizations on $30^{\circ}$ [In same direction].

4. Cluster spatial organizations on $30^{\circ}$ [In different direction].

5. Cluster spatial organizations on $45^{\circ}$ [In same direction].

6. Cluster spatial organizations on $45^{\circ}$ [In different direction].

7. Cluster spatial organizations on $60^{\circ}$ [In same direction].

8. Cluster spatial organizations on $60^{\circ}$ [In different direction].

9. Spatial organizations as collective spaces. 


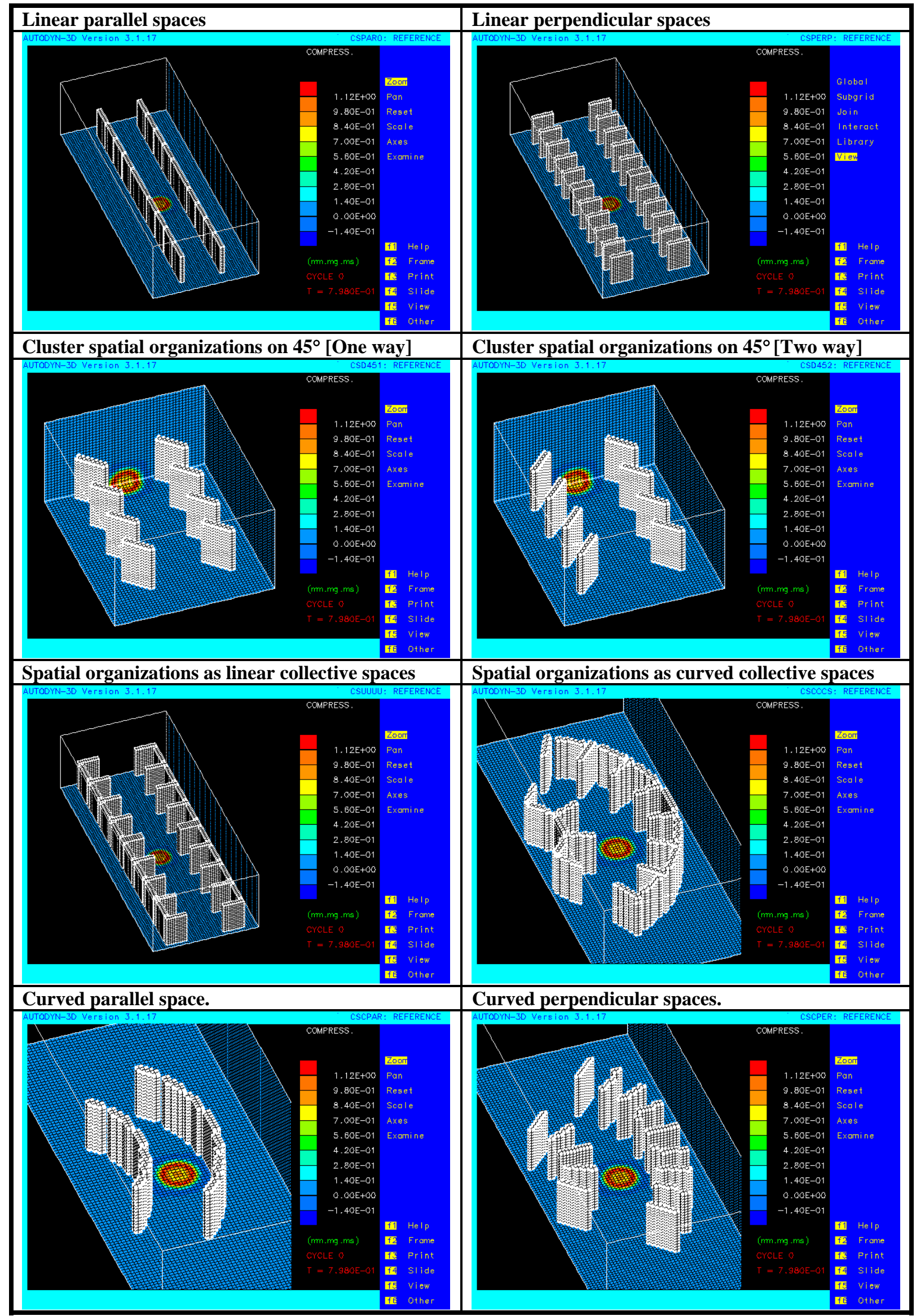

Fig.4 Examples of AUTODYN simulation 


\section{Group B: Curved Street Shape:}

1. Spatial organizations as parallel linear spaces. [Reference scenario].

2. Spatial organizations as perpendicular linear spaces.

3. Spatial organizations as collective spaces.

\section{Reference scenario:}

The geometry of LDS, for each simulation group with width $16 \mathrm{~m}$. , length $90 \mathrm{~m}$. and buildings height $16 \mathrm{~m}$. is selected as a reference scenario, with which all simulations of each group will be compared. The location of the blast was taken to be with a vehicle bomb at the middle of vulnerable street.

An average of impulse values is presented for specific 15 target points located on assumed building sited at the middle of vulnerable street width and at the end of its length, as shown in figure 4. The AUTODYN simulation package 3D V3.1.17 was used to evaluate the pressure and impulse values on the structure and the ConWep program [4] validated these values.



Fig.5 Reference Scenario of Straight street simulations group. 


\section{RESULTS}

After executing the whole series of simulations (108 simulations) (figure 4 shows a simulations example), tabulating, analysed and comparing the output values of impulse, a group of results was deduced as follows:

\section{Spatial organizations:}

\section{- Group A: Straight Street Shape.}

Figure 6 shows the reduction, compared to the reference scenario, of impulse values of specific points located on the target structure (Fig. 5). It indicates that:

(a) The spatial organization as collective spaces reduces the impulse values up to $50 \%$, when compared with the reference scenario as shown in figure 5.

(b) The spatial organization as perpendicular linear spaces reduces the impulse values up to $70 \%$, when compared with the reference scenario.

(c) The spatial organization as cluster spaces reduces the impulse values up to $67-72 \%$, when compared with the reference scenario.



Fig.6 Decrease in impulse values of group A' simulations.

\section{- Group B: Curved Street Shape:}

Figure 7 shows the reduction, compared to the reference scenario, of impulse values of specific points located on the target structure. It indicates that:

a) The spatial organizations as collective spaces reduce the impulse values up to $74 \%$, when compared with the reference scenario. 
b) The spatial organizations as perpendicular linear spaces reduce the impulse values up to $80 \%$, when compared with the reference scenario.

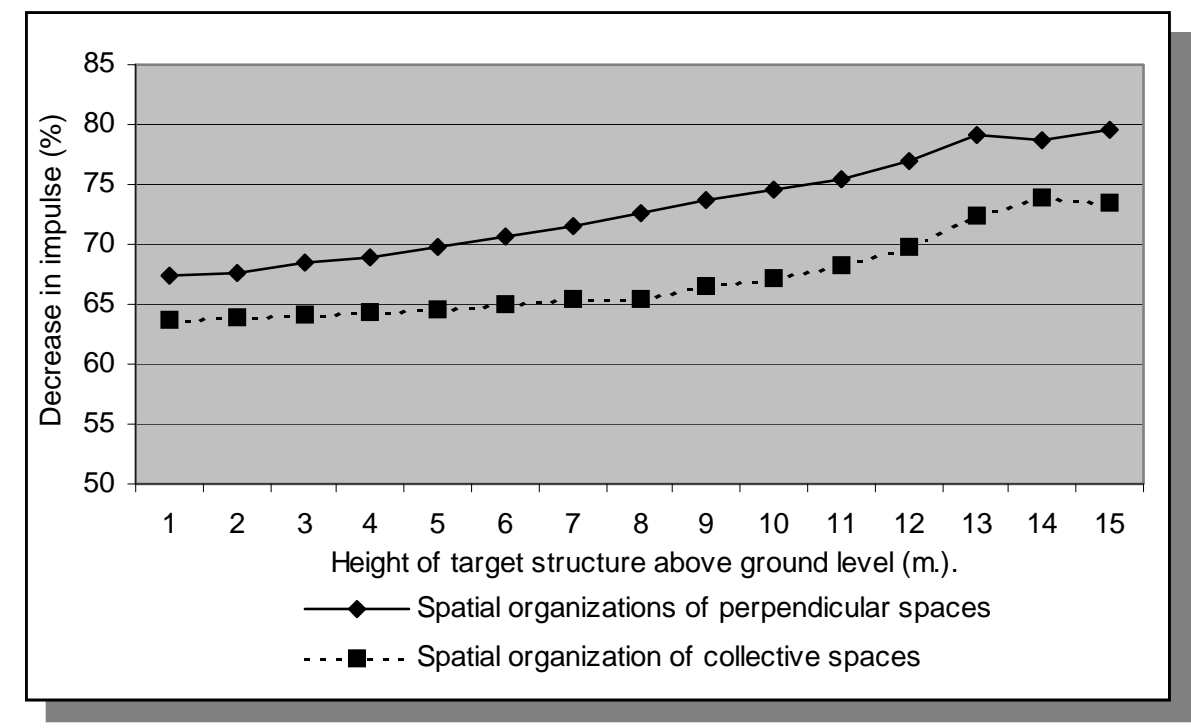

Fig.7 Decrease in impulse values of group B’ simulations.

\section{Street shape configuration:}

a) Generally, the output impulse values of all simulations indicates that curved street shape can offer reduction in the effects of blast waves up to $20 \%$ less than straight street shape.

b) The spatial organizations, especially cluster spaces, can offer spaces between the buildings large enough to act as venting openings, which helping to reduce the effects of blast waves through the urban environment.

\section{CONCLUSIONS}

1) The site selection process for specific buildings, which could be subjected to terrorist attack, should be taken in consideration not only as an architectural parameter of the buildings but also as a planning parameter for the surrounding urban environment.

2) Specific spatial organizations of urban street can have a significant reduction in the effects of the blast waves on the structure and the surrounding environment.

3) Using specific spatial organizations to reduce the effects the blast waves can be achieved without affecting the functionality of the structures and street spaces.

4) Street venting can offer significant reductions in the effects of the blast waves, which generate in the surrounding environment.

\section{REFERENCES}

[1] Autodyn 3D V3.1.17, Century Dynamics Limited, 12 City Business Centre, Brighton Road, Horsham, England, (1999). 
[2] Roads in urban areas, Department of the environment, Scottish Development Department, the Welsh office (1993).

[3] Responsive Environments, I. Bently, A. Alcock, P. Murrain, S. McGlynn, G. Smith, Architecture department and joint Centre for Urban Design, Oxford polytechnic. (1996).

[4] ConWep, U.S. Army Engineer Waterways Experiment Station, 3909 Halls Ferry Road, Vicksburg, MS 39180, (1991). 